\title{
Intensified low-density lipoprotein- cholesterol target of statin therapy and cancer risk: a meta-analysis
}

\author{
Haixia Sun, Yang Yuan, Pin Wang, Rongrong Cai, Wenqing Xia, Rong Huang and Shaohua Wang*
}

\begin{abstract}
Background: This study aimed to investigate the relationship between an intensified low-density lipoproteincholesterol (LDL-C) target of statin therapy and cancer risk.

Methods: Data from PUBMED, EMBASE, and the Cochrane Central Register of Controlled Trials as of September 2014 were searched for randomized controlled trials on statins. An intensified LDL-c target of $<2.59 \mathrm{mmol} / \mathrm{L}$ $(100 \mathrm{mg} / \mathrm{dL})$ or a relative $\mathrm{LDL}-\mathrm{c}$ reduction by at least $30 \%$ of the baseline was the primary criterion for all the trials that were included in this meta-analysis. The $P^{2}$ statistic was used to measure heterogeneity among the trials, and risk estimates were calculated for cancer incidence in this random-effect meta-analysis.

Results: Nine eligible studies were identified with 59,571 participants, of whom 5379 developed cancer during the follow-up period (2691 were given statins and 2688 were given control treatment). The intensified LDL-c target of statin therapy did not affect cancer incidence (odds ratio, 1.00; $95 \%$ confidence interval, $0.94-1.06 ; P^{2}=1.6 \%, p=0.42$ ), which included some common cancers. Subgroup analysis showed that neither the chemical properties nor the variety of the statins accounted for the residual variation in risk.

Conclusions: The intensified LDL-c target of statin therapy had no effect on the overall incidence of cancer, including some common cancers. Therefore, intensified statin therapy does not need to be changed among adult clinical patients.
\end{abstract}

Keywords: Intensified LDL-c target of statin therapy, Cancer, LDL-C

\section{Introduction}

Statin therapy has been proven to help prevent cardiovascular events and mortality [1-6]. Intensified lowdensity lipoprotein-cholesterol (LDL-c) targets of statin therapy, which are highly accurate, have also been widely used in clinical practice, especially among high-risk patients. The third report of an expert panel on the detection, evaluation, and treatment of high blood cholesterol in adults (Adult Treatment Panel ATP III, 2001) recommended a LDL-c goal of $<100 \mathrm{mg} / \mathrm{dL}$ for patients with coronary heart disease (CHD) and CHD risk equivalents (10-year risk > $20 \%$; Framingham risk score) [7]. Among diabetic patients, the dyslipidemia control criteria recommend LDL-c $<2.59 \mathrm{mmol} / \mathrm{L}$ for diabetic patients and

\footnotetext{
* Correspondence: gyjwsh@126.com

Department of Endocrinology, The Affiliated ZhongDa Hospital of Southeast University, No.87 Ding JiaQiao Road, Nanjing 210009, PR China
}

LDL-c $<2.07 \mathrm{mmol} / \mathrm{L}(80 \mathrm{mg} / \mathrm{dL})$ for diabetic patients with cardiovascular disease in China $[8,9]$. The American Association of Clinical Endocrinologists 2012 guidelines recommend LDL-c $<100 \mathrm{mg} / \mathrm{dL}$ for high-risk patients $(\geq 2$ major risk factors and Framingham risk score $>20 \%$ CHD risk equivalent) [10]. The intensified LDL-c target of statin therapy in this meta-analysis was defined as a target of LDL-c $<$ $2.59 \mathrm{mmol} / \mathrm{L}(100 \mathrm{mg} / \mathrm{dL})$ or a relative $\mathrm{LDL}-\mathrm{c}$ reduction of at least $30 \%$ of the baseline [11].

Nevertheless, some side effects of statin therapy and the intensified LDL-c target of statin therapy have been reported (e.g., cancer risk). Several studies have reported the relationship between statin therapy and cancer risk [12-18]. A considerable amount of scholars believe that statin therapy has no relationship with cancer risk or statin therapy may prevent cancer, despite contradictory 
findings in the literature [15-18]. For instance, a significant decrease in HR-negative breast cancer was reported among statin users in a previous study [15]. A recently published systematic review and meta-analysis reported that statins have no effect on the overall incidence of cancer [17]. Few studies investigated the correlation between the intensified LDL-c target of statin therapy and cancer risk, but the same indefinite conclusion was obtained. Low risk of cancer was found for patients treated with high-efficacy statins in a recent populationbased study (LDL-c reduction: low, $\leq 30 \%$; moderate, 31-40\%; high, $\geq 41 \%)[19,20]$. However, a previous study showed that cancer incidence did not increase in the group achieving LDL-C $<30 \mathrm{mg} / \mathrm{dL}$ after highintensity statin therapy compared with the controls [21].

The relationship between the intensified LDL-c target of statin therapy and cancer risk has been investigated for a long time, but results remain inconsistent. Thus, we aimed to investigate whether the intensified LDL-c target of statin therapy contributes to the onset of carcinoma according to the findings of previous metaanalyses and recent randomized controlled trials (RCTs).

\section{Methods}

\section{Ethics}

The protocol of the current study was approved by the research ethics committees of ZhongDa Hospital, which was affiliated with Southeast University.

\section{Search strategy}

To obtain all of the original studies on the effect of intensified LDL-c target of statin therapy on cancer incidence in adult patients, we searched potentially eligible studies in the electronic databases PUBMED, EMBASE, and Cochrane as of September 2014. The following medical subject headings and free text keywords were used: "hydroxymethylglutaryl coenzyme A reductase inhibitor," "statins," "statin," "fluvastatin," "mevastatin," "compactin," "pravastatin," "simvastatin," "lovastatin," "pitavastatin," "rosuvastatin," "cerivastatin", "atorvastatin," "cancer," "carcinoma," "neoplasm," "tumor," "phyma," "randomized controlled trial," and "human".

\section{Selection criteria}

We included the RCTs if one of the endpoint or study assesses the effect of intensified LDL-c target of statin therapy on cancer endpoints in adult patients. The inclusion criteria used for the search are described as follows. The study should be an original work comparing statin treatment with an inactive control (placebo or no statins) involving more than 1000 adult study participants (18 years and older) whose cancer incidence was reported and followed-up for over one year. The patients included in the report should have achieved an intensified LDL-c target of $<2.59 \mathrm{mmol} / \mathrm{L}(100 \mathrm{mg} / \mathrm{dl})$ or a relative LDL-c reduction of at least $30 \%$ of the baseline. We excluded comparison trials involving either different statins or different doses of the same statin as well as trials on patients with cancer.

\section{Data sources}

For all of the published trials, the following details were recorded: study characteristics (study design and allocation), participants (baseline age, sample size, and accompanying disease), therapeutic intervention (type of statin, dose of statin, and duration of therapy), and new cancer cases. Moreover, we recorded the endpoint LDL-c concentrations and relative reduction in LDL-c concentrations during the statin therapy to verify whether the intensified LDL-c target of statin therapy correlates with the incidence of cancer.

For trials with unpublished information, we formally requested data using a question sheet. The questions covered the number of incident cancer in specific sites (e.g., central nervous system (CNS), skin, breast, respiratory, gastrointestinal, and hematological). However, the replies were unclear, or no reply was received.

\section{Statistical analysis}

To determine the potential effects of the intensified LDL-c target of statin therapy on the incidence of cancer, odds ratio (OR) and $95 \%$ confidence interval (CI) were used to compare the mean differences in each subgroup separately. We evaluated the statistical heterogeneity between trials with the $I^{2}$ statistic (with $95 \%$ CIs), which is derived from Cochran's Q $(100 \times(\mathrm{Q}-\mathrm{df}) / \mathrm{Q})$ [22] and provides a measure of the overall variation that is attributed to between-trial heterogeneity. Random-effect meta-analysis was performed instead of the fixed-effect model because the former approach provides a more conservative assessment (e.g., broad CIs) of the average effect size. Subgroup analyses were used to investigate the potential sources of heterogeneity between trials. The factors that were investigated included the type of statin, dose of statin, and relative reduction in LDL-c concentrations. We analyzed the data with Stata version 11.0.

A funnel plot and Egger's test were used to test for publication bias [23]. We conducted meta-analyses that included all trials; different types of statin (simvastatin, rosuvastatin, atorvastatin, pravastatin, and fluvastatin); comparison trials with hydrophilic (pravastatin and rosuvastatin) and lipophilic (atorvastatin, simvastatin, and fluvastatin) statins; trials with specific cancer according to available date (respiratory, gastrointestinal, genitourinary and CNS). Additionally, we performed the sensitivity analysis with Stata version 11.0. 


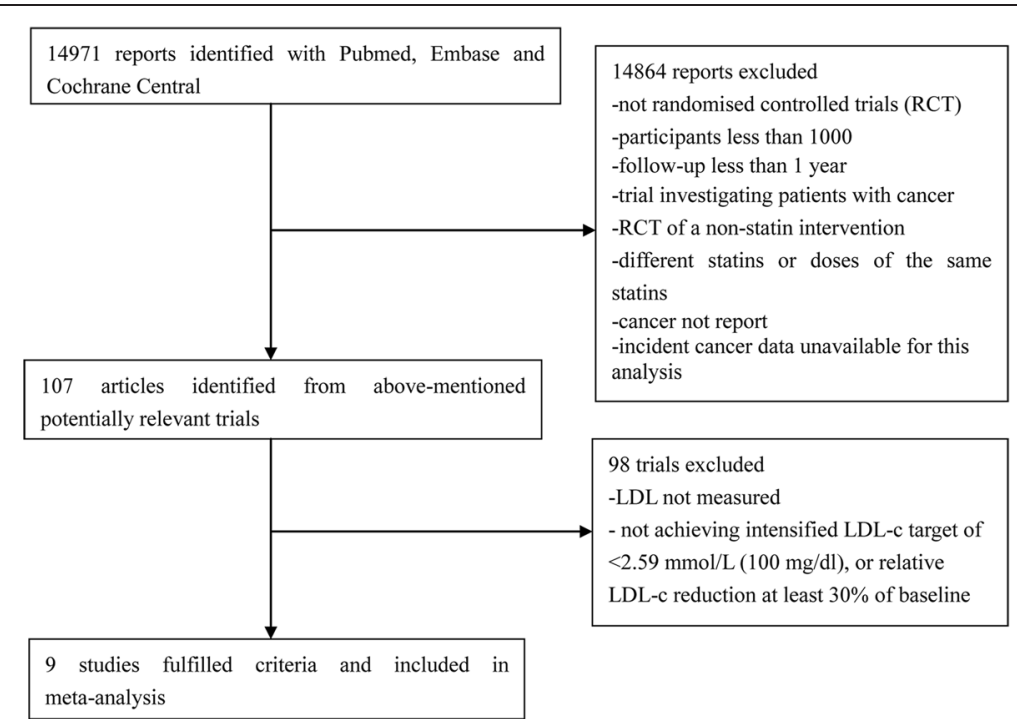

Fig. 1 Flow diagram of literature search to identify randomised placebo-controlled or standard care-controlled statin trials

\section{Results}

\section{Description of the studies}

We identified nine trials involving 59,571 non-cancer participants, of whom 5379 developed cancer (Fig. 1). Five different statins were studied, with a follow-up duration of 1.9-16.3 years. The characteristics of the included studies are summarized in Tables 1 and 2 .

\section{Effects of the intensified LDL-c target of statin therapy on the overall incidence of cancer \\ Any statin}

The intensified LDL-c target of statin therapy did not affect the overall incidence of cancer (OR, 1.00; $95 \% \mathrm{CI}$, $0.94-1.06 ; I^{2}=1.6 \%, p=0.42$; Fig. 2 ). Among the nine trials, only the PROSPER (pravastatin in elderly individuals at risk of vascular disease) study [13] showed that the intensified LDL-c target of pravastatin therapy promoted cancer incidence (Fig. 2).

We also performed sensitivity analysis, which suggested that the combination of all trials in the primary analysis was appropriate. Additionally, we conducted a funnel plot and Egger's test for all nine trials and found no underlying publication bias.

\section{Different statins}

The subgroup analyses of the individual statin that met the intensified LDL-c target revealed no significant effect on the incidence of cancer. Pravastatin therapy was

Table 1 Characters for non-cancer participants in nine placebo-controlled and standard care-controlled statin trials

\begin{tabular}{|c|c|c|c|c|c|c|c|}
\hline Study & Year & $\begin{array}{l}\text { Number of } \\
\text { participants }\end{array}$ & Type & $\begin{array}{l}\text { Mean follow-up } \\
\text { (years) }\end{array}$ & Age (years) & Statin & $\begin{array}{l}\text { Jadad } \\
\text { Score }\end{array}$ \\
\hline HPS & 2011 & 20536 & At increased risk of vascular events & 16.3 & $40-80$ & simvastatin $40 \mathrm{mg}$ & 5 \\
\hline AURORA & 2009 & 2773 & With maintenance hemodialysis & 3.2 & $50-80$ & rosuvastatin $10 \mathrm{mg}$ & 5 \\
\hline CARDS & 2008 & 2838 & $\begin{array}{l}\text { With type } 2 \text { diabetes and no history } \\
\text { of coronary heart disease (CHD) }\end{array}$ & 3.9 & $40-75$ & atorvastatin $10 \mathrm{mg}$ & 4 \\
\hline JUPITER & 2008 & 17802 & Healthy & 1.9 & $\begin{array}{l}50 \text { years and } \\
\text { older }\end{array}$ & rosuvastatin $20 \mathrm{mg}$ & 6 \\
\hline GDDS & 2005 & 1255 & $\begin{array}{l}\text { With type } 2 \text { diabetes receiving } \\
\text { maintenance hemodialysis }\end{array}$ & 4 & $18-80$ & atorvastatin $20 \mathrm{mg}$ & 7 \\
\hline ALLIANCE & 2004 & 2442 & CHD patients with hyperlipidemia & 4.3 & $\begin{array}{l}61.1 \text { (atorvastotin)/ } \\
61.3 \text { (usual-care) }\end{array}$ & $\begin{array}{l}\text { a maximum atorvastatin } \\
\text { dose of } 80 \mathrm{mg} / \text { day }\end{array}$ & 3 \\
\hline PROSPER & 2002 & 5804 & $\begin{array}{l}\text { With a history of, or risk factors } \\
\text { for, vascular disease }\end{array}$ & 3.2 & $70-82$ & pravastatin $40 \mathrm{mg}$ & 6 \\
\hline LIPS & 2002 & 1677 & $\begin{array}{l}\text { After successful first } \\
\text { percutaneouscoronary } \\
\text { intervention (PCI) }\end{array}$ & 3.9 & $18-80$ & fluvastatin $80 \mathrm{mg}$ & 6 \\
\hline 45 & 1994 & 4444 & With CHD & 5.4 & $35-70$ & simvastatin $20 \mathrm{mg}$ & 5 \\
\hline
\end{tabular}


Table 2 Characters for non-cancer participants in nine placebo-controlled and standard care-controlled statin trials

\begin{tabular}{|c|c|c|c|c|c|c|c|c|}
\hline Study & Cancer outcome & $\begin{array}{l}\text { Relative } L D L-c \\
\text { reduction }\end{array}$ & $\begin{array}{l}\text { endpoint } \\
\text { LDL-c (mmol/L) }\end{array}$ & $\begin{array}{l}\text { New } \\
\text { cancer } \\
\text { cases }\end{array}$ & $\begin{array}{l}\text { Number in } \\
\text { statin group }\end{array}$ & $\begin{array}{l}\text { Number in } \\
\text { control group }\end{array}$ & $\begin{array}{l}\text { New cancer in } \\
\text { satin group }\end{array}$ & $\begin{array}{l}\text { New cancer in } \\
\text { control group }\end{array}$ \\
\hline HPS & $\begin{array}{l}\text { CNS, Gastrointestinal, } \\
\text { genitourinary, respiratory et al. }\end{array}$ & $32.35 \%$ & 2.3 & 3493 & 10269 & 10267 & 1749 & 1744 \\
\hline AURORA & Not specified & $43 \%$ & 1.1 & 225 & 1389 & 1384 & 107 & 118 \\
\hline CARDS & Not specified & $\begin{array}{l}\text { below } \\
2.59 \mathrm{mmol} / \mathrm{L}\end{array}$ & 1.99 & 141 & 1428 & 1410 & 69 & 72 \\
\hline JUPITER & Not specified & $49 \%$ & 1.42 & 612 & 8901 & 8901 & 298 & 314 \\
\hline GDDS & Not specified & $42 \%$ & 1.86 & 83 & 619 & 636 & 39 & 44 \\
\hline ALLIANCE & Not specified & $34.30 \%$ & 2.5 & 144 & 1217 & 1225 & 67 & 77 \\
\hline PROSPER & $\begin{array}{l}\text { Gastrointestinal, genitourinary, } \\
\text { respiratory et al. }\end{array}$ & $34 \%$ & 2.5 & 444 & 2891 & 2913 & 245 & 199 \\
\hline LIPS & $\begin{array}{l}\text { Gastrointestinal, genitourinary, } \\
\text { respiratory, CNS et al. }\end{array}$ & $\begin{array}{l}\text { below } \\
2.59 \mathrm{mmol} / \mathrm{L}\end{array}$ & 2.48 & 32 & 844 & 833 & 14 & 18 \\
\hline $4 S$ & Gastrointestinal & $35 \%$ & 3.17 & 205 & 2221 & 2223 & 103 & 102 \\
\hline TOTAL & & & & 5379 & 29779 & 29792 & 2691 & 2688 \\
\hline
\end{tabular}

\begin{tabular}{|c|c|c|}
\hline Study & & $\%$ \\
\hline ID & OR (95\% Cl) & Weight \\
\hline HPS & $1.00(0.93,1.08)$ & 59.27 \\
\hline AURORA & $0.90(0.68,1.18)$ & 4.77 \\
\hline CARDS & $0.94(0.67,1.32)$ & 3.11 \\
\hline JUPTER & $0.95(0.81,1.11)$ & 13.40 \\
\hline GDDS & $0.90(0.58,1.41)$ & 1.80 \\
\hline ALLIANCE & $0.87(0.62,1.22)$ & 3.13 \\
\hline PROSPER & $1.26(1.04,1.53)$ & 9.29 \\
\hline LIPS & $0.76(0.38,1.55)$ & 0.72 \\
\hline $4 S$ & $1.01(0.76,1.34)$ & 4.52 \\
\hline Overall $(1-$ squared $=1.6 \%, p=0.420)$ & $1.00(0.94,1.06)$ & 100.00 \\
\hline \multicolumn{3}{|l|}{ NOTE: Weights are from random effects analysis } \\
\hline .377 & & \\
\hline
\end{tabular}

Fig. 2 Association between intensified LDL-c target of statin therapy and incident cancer in 9 major trials. Legend: The intensified LDL-c target of statin therapy has no effect on the overall incidence of cancer 
found to promote cancer incidence (OR, 1.26; $95 \% \mathrm{CI}$, $1.04-1.53)$. The subgroup analyses of fluvastatin therapy [24] showed no effects on cancer incidence (OR, 0.76; $95 \%$ CI, $0.38-1.55$ ). This result (Fig. 3) was similar to that of simvastatin therapy (OR, 1.00; $95 \% \mathrm{CI}$, $\left.0.94-1.08 ; I^{2}=0.0 \%, p=0.957\right)[25,26]$, rosuvastatin therapy (OR, 0.93; $95 \% \mathrm{CI}, 0.81-1.07 ; I^{2}=0.0 \%$, $p=0.728)[6,27]$, and atorvastatin therapy (OR, 0.91; $\left.95 \% \mathrm{CI}, 0.73-1.12 ; I^{2}=0.0 \%, p=0.944\right)$ [28-30].

Lipophilic and hydrophilic statins

Given that the chemical properties of statins may lead to different results from our previous findings, statins were divided into two groups, namely, the lipophilic and hydrophilic statins, in another subgroup analysis. Neither the lipophilic (OR, 0.99; 95 \% CI, 0.93 - 1.06; Fig. 4). nor hydrophilic (OR, 1.03; 95 \% CI, 0.84-1.27; Fig. 4). statins that met the intensified LDL-c target affected the incidence of cancer.

Effects of the intensified LDL-c target of statin therapy on cancer at specific sites

We also conducted subgroup analyses on site-specific cancer. However, the available data are limited. We only performed subgroup analyses on respiratory, CNS, gastrointestinal, and genitourinary cancers based on the present data. No relationship was found between the intensified LDL-c target of statin therapy and the incidence of respiratory cancer (OR, 1.05; $95 \% \mathrm{CI}, 0.91$ $\left.1.21 ; I^{2}=0.0 \%, p=0.794\right)$, CNS cancer (OR, $0.71 ; 95 \%$ CI, $\left.0.09-5.55 ; I^{2}=55.5 \%, p=0.134\right)$, gastrointestinal cancer (OR, 1.11; $95 \%$ CI, $0.80-1.54, I^{2}=54.2 \%$, $p=0.088$ ), and genitourinary cancer (OR, 1.02; $95 \% \mathrm{CI}$, $\left.0.91-1.14 ; I^{2}=0.0 \%, p=0.986\right)$.

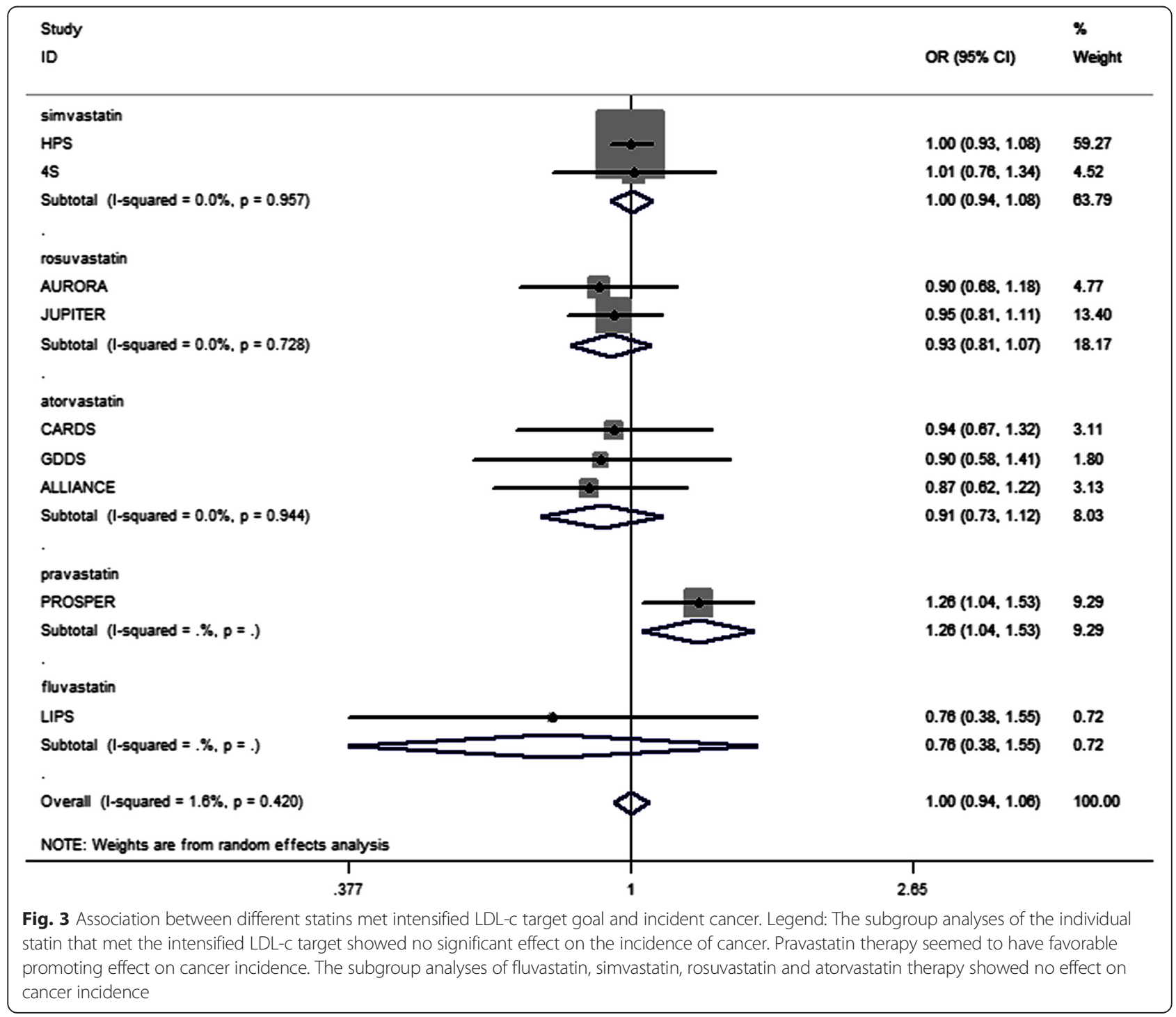




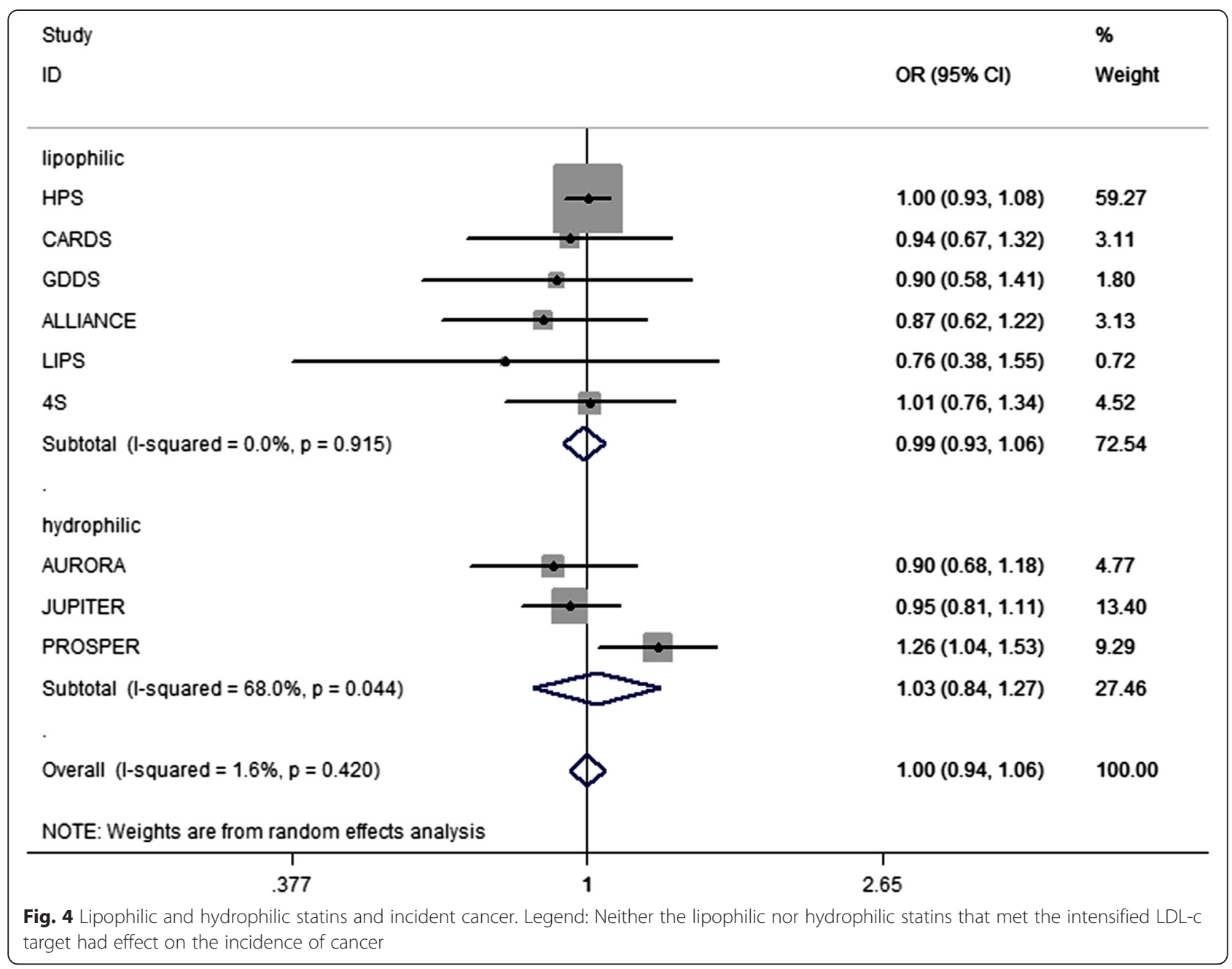

\section{Discussion}

The intensified LDL-c target of statin therapy, with the goal of achieving LDL-c $<2.59 \mathrm{mmol} / \mathrm{L}(100 \mathrm{mg} / \mathrm{dl})$ or a relative LDL-c reduction by at least $30 \%$ of the baseline after statin treatment, is commonly used in clinical trials and is believed to be effective. The intensified LDL-c target of statin therapy is suitable for the general population. For example, according to previous reports, all patients with peripheral arterial disease or those with familial hypercholesterolemia benefit from the intensified LDL-c target of statin therapy [31, 32]. Furthermore, this approach is appropriate and widely used in high-risk populations, such as diabetics with cardiovascular and cerebrovascular diseases. These patients are known to be at high risk of cancer incidence, so lipid control appears worthwhile. The dyslipidemia control criteria recommend LDL-c $<2.59 \mathrm{mmol} / \mathrm{L}$ for diabetic patients, and LDL-c $<2.07 \mathrm{mmol} / \mathrm{L}(80 \mathrm{mg} / \mathrm{dL})$ for diabetic patients with cardiovascular disease [8, 9]. Numerous studies have explored the relationship between statins and cancer incidence. However, reports on the effect of the intensified LDL-c target of statin therapy on the incidence of cancer are relatively few. The present comprehensive meta-analysis was performed to provide evidence to clinicians and patients, which can also improve patient compliance.

Our meta-analysis showed that the intensified LDL-c target of statin therapy had no effect on the overall incidence of cancer, including some common cancers. The results of this meta-analysis were relatively stable according to sensitivity analysis. Begg's funnel plot and Egger's test showed no underlying publication bias.

In the studies selected for our meta-analysis, PROSPER [13] indicated that pravastatin may increase cancer risk. However, when the authors of the PROSPER [13] study extended their follow-up period to 14 years, no relationship was found between statin use and cancer risk [33]. Another study showed that pravastatin therapy presented an increasing risk of cancer incidence with rising patient age [34]. Nevertheless, the findings on pravastatin 
need to be confirmed by further studies. To date, clinical statin therapy has no special significance according to our subgroup analysis.

Previous studies have shown that statin therapy may inhibit cancer. For example, a recent trial revealed that a cumulative amount of statin use may decrease prostatic cancer risk [35]. In a recently published study, lipophilic statin was reported to play a therapeutic role in cancer treatment [36]. Statins may inhibit HMG-CoA reductase to lower the concentration of mevalonate, thereby decreasing the amount of isoprenylated intermediates that are known to affect signaling pathways, from cancer formation to progression [37].

Given the confusing association between statin therapy and cancer risk, as well as increasing incidence of cancer, we conducted subgroup analyses on sitespecific cancer. The results showed the absence of a relationship between the intensified LDL-c target of statin therapy and the incidence of respiratory, CNS, gastrointestinal, and genitourinary cancers. To determine the safety of clinical statin treatment, we should investigate the relationship between the intensified LDL-c target of statin therapy and the risk of individual cancers in the future.

Several limitations of our study should be noted. First, the number of studies included in our meta-analysis is limited, especially for some individual statin. Second, sufficient evidence was unavailable to support or contradict the finding that pravastatin may promote cancer incidence. Third, available evidence from unpublished data on site-specific cancer is limited.

\section{Conclusion}

The intensified LDL-c target of statin therapy did not affect the overall incidence of cancer, including some common cancers, among adult patients. Therefore, the intensified therapy does not need to be changed among adult patients in clinical applications.

\section{Abbreviations \\ LDL-C: Low-density lipoprotein-cholesterol; CHD: Coronary heart disease; RCT: Randomized controlled trial; CNS: Central nervous system; OR: Odds ratio; Cl: Confidence interval.}

\section{Competing interests}

The authors declare that they have no competing interests.

\section{Authors' contributions}

SHX, YY, WP and CRR performed this study, SHX, XWQ and HR performed statistic analyses, SHX and WSH designed this study and SHX wrote this article. All authors read and approved the final manuscript.

\section{Acknowledgement}

This work was partially supported by the National Natural Science Foundation of China (No. 81370921, Wang SH; No. 81570732, Wang SH; and No. 81070916, Guo YJ), the Social Development Project of JiangSu Province (No. SBE201170735, Wang SH), the National Nature Science Youth Foundation of China (No. 81200635, Yang Y), and the National Nature Science Foundation of Jiangsu Province (No. SBK201122155, Yang Y).
Received: 20 June 2015 Accepted: 28 October 2015

Published online: 02 November 2015

\section{References}

1. Baigent C, Keech A, Kearney PM, Blackwell L, Buck G, Pollicino C, et al. Efficacy and safety of cholesterol-lowering treatment: prospective metaanalysis of data from 90,056 participants in 14 randomised trials of statins. Lancet. 2005;366:1267-78.

2. Holdaas H, Fellstrom B, Jardine AG, Holme I, Nyberg G, Fauchald P, et al. Effect of fluvastatin on cardiac outcomes in renal transplant recipients: a multicentre, randomised, placebo-controlled trial. Lancet. 2003;361:2024-31.

3. Thavendiranathan P, Bagai A, Brookhart MA, Choudhry NK. Primary prevention of cardiovascular diseases with statin therapy: a meta-analysis of randomized controlled trials. Arch Intern Med. 2006;166:2307-13.

4. Sever PS, Dahlof B, Poulter NR, Wedel H, Beevers G, Caulfield M, et al. Prevention of coronary and stroke events with atorvastatin in hypertensive patients who have average or lower-than-average cholesterol concentrations, in the Anglo-Scandinavian Cardiac Outcomes Trial - Lipid lowering arm (ASCOT-LLA): a multicentre randomised controlled trial. Drugs. 2004;64:43-60.

5. Ford I, Murray H, Packard CJ, Shepherd J, Macfarlane PW, Cobbe SM, et al. Long-term follow-up of the West of Scotland Coronary Prevention Study. N Engl J Med. 2007;357:1477-86.

6. Ridker PM, Danielson E, Fonseca FA, Genest J, Gotto Jr AM, Kastelein JJ, et al. Rosuvastatin to prevent vascular events in men and women with elevated C-reactive protein. N Engl J Med. 2008;359:2195-207.

7. Expert Panel on Detection E, Treatment of High Blood Cholesterol in A. Executive summary of the third report of The National Cholesterol Education Program (NCEP) expert panel on detection, evaluation, and treatment of high blood cholesterol in adults (Adult Treatment Panel III). JAMA. 2001;285:2486-97.

8. Wang SH, Wang L, Zhou Y, Guo YJ, Yuan Y, Li FF, et al. Prevalence and control of dyslipidaemia among diabetic patients with microalbuminuria in a Chinese hospital. Diab Vasc Dis Res. 2013;10:169-78.

9. American Diabetes Association. Standards of medical care in diabetes_2011. Diabetes Care. 2011;34 Suppl 1:S11-61.

10. Garber JR, Cobin RH, Gharib H, Hennessey JV, Klein I, Mechanick Jl, et al. Clinical practice guidelines for hypothyroidism in adults: cosponsored by the American Association of Clinical Endocrinologists and the American Thyroid Association. Endocr Pract. 2012;18:988-1028.

11. Grundy SM, Cleeman JI, Merz CN, Brewer Jr HB, Clark LT, Hunninghake DB, et al. Implications of recent clinical trials for the National Cholesterol Education Program Adult Treatment Panel III Guidelines. J Am Coll Cardiol. 2004:44:720-32.

12. Newman TB, Hulley SB. Carcinogenicity of lipid-lowering drugs. JAMA. 1996;275:55-60.

13. Shepherd J, Blauw GJ, Murphy MB, Bollen EL, Buckley BM, Cobbe SM, et al. Pravastatin in elderly individuals at risk of vascular disease (PROSPER): a randomised controlled trial. Lancet. 2002;360:1623-30.

14. Hunt D, Young P, Simes J, Hague W, Mann S, Owensby D, et al. Benefits of pravastatin on cardiovascular events and mortality in older patients with coronary heart disease are equal to or exceed those seen in younger patients: Results from the LIPID trial. Ann Intern Med. 2001;134:931-40.

15. Kumar AS, Benz CC, Shim V, Minami CA, Moore DH, Esserman L. Estrogen receptor-negative breast cancer is less likely to arise among lipophilic statin users. Cancer Epidemiol Biomark Prev. 2008;17:1028-33.

16. Bansal D, Undela K, D'Cruz S, Schifano F. Statin use and risk of prostate cancer: a meta-analysis of observational studies. PLoS One. 2012;7:e46691.

17. Kuoppala J, Lamminpaa A, Pukkala E. Statins and cancer: a systematic review and meta-analysis. Eur J Cancer. 2008;44:2122-32.

18. Tan M, Song X, Zhang G, Peng A, Li X, Li M, et al. Statins and the risk of lung cancer: a meta-analysis. PLoS ONE. 2013;8:e57349.

19. Lutski M, Shalev V, Porath A, Chodick G. Continuation with statin therapy and the risk of primary cancer: a population-based study. Preventing Chronic Disease. 2012;9.

20. Valuck RJ, Williams SA, MacArthur M, Saseen JJ, Nair KV, McCollum M, et al. A retrospective cohort study of correlates of response to pharmacologic therapy for hyperlipidemia in members of a managed care organization. Clin Ther. 2003;25:2936-57. 
21. Everett BM, Mora S, Glynn RJ, MacFadyen J, Ridker PM. Safety profile of subjects treated to very low low-density lipoprotein cholesterol levels $(<30 \mathrm{mg} / \mathrm{dl})$ with rosuvastatin 20 mg daily (from JUPITER). Am J Cardiol. 2014;114:1682-9.

22. Higgins JPT, Thompson SG, Deeks JJ, Altman DG. Measuring inconsistency in meta-analyses. Br Med J. 2003;327:557-60.

23. Egger M, Smith GD, Schneider M, Minder C. Bias in meta-analysis detected by a simple, graphical test. Br Med J. 1997;315:629-34.

24. Serruys PWJC, de Feyter P, Macaya C, Kokott N, Puel J, Vrolix M, et al. Fluvastatin for prevention of cardiac events following successful first percutaneous coronary intervention-A randomized controlled trial. JAMA. 2002;287:3215-22.

25. Bulbulia R, Bowman L, Wallendszus K, Parish S, Armitage J, Peto R, et al. Effects on 11-year mortality and morbidity of lowering LDL cholesterol with simvastatin for about 5 years in 20536 high-risk individuals: a randomised controlled trial. Lancet. 2011;378:2013-20.

26. Pedersen TR, Kjekshus J, Berg K, Haghfelt T, Faergeman O, Thorgeirsson G, et al. Randomized trial of cholesterol-lowering in 4444 patients with coronary-heart-disease - the Scandinavian Simvastatin Survival Study (45). Lancet. 1994;344:1383-9.

27. Fellstrom BC, Jardine AG, Schmieder RE, Holdaas H, Bannister K, Beutler J, et al. Rosuvastatin and cardiovascular events in patients undergoing hemodialysis. N Engl J Med. 2009;360:1395-407.

28. Newman CB, Szarek M, Colhoun HM, Betteridge DJ, Durrington PN, Hitman $\mathrm{GA}$, et al. The safety and tolerability of atorvastatin $10 \mathrm{mg}$ in the Collaborative Atorvastatin Diabetes Study (CARDS). Diab Vasc Dis Res. 2008:5:177-83.

29. Wanner C. Atorvastatin in patients with type 2 diabetes mellitus undergoing hemodialysis (vol 353, pg 238, 2005). N Engl J Med. 2005;353:1640-1640.

30. Koren MJ, Hunninghake DB, Investigators A. Clinical outcomes in managedcare patients with coronary heart disease treated aggressively in lipidlowering disease management clinics - The ALLIANCE study. J Am Coll Cardiol. 2004;44:1772-9.

31. Feringa $\mathrm{HHH}$, Karagiannis $\mathrm{SE}$, van Waning $\mathrm{VH}$, Boersma E, Schouten $\mathrm{O}$, Bax JJ, et al. The effect of intensified lipid-lowering therapy on long-term prognosis in patients with peripheral arterial disease. J Vasc Surg. 2007:45:936-43.

32. Kastelein JJP, Akdim F, Stroes ESG, Zwinderman AH, Bots ML, Stalenhoef AFH, et al. Simvastatin with or without ezetimibe in familial hypercholesterolemia. N Engl J Med. 2008:358:1431-43.

33. Jukema JW, Cannon CP, de Craen AJM, Westendorp RGJ, Trompet S. The controversies of statin therapy weighing the evidence. J Am Coll Cardiol. 2012;60:875-81.

34. Bonovas S, Sitaras NM. Does pravastatin promote cancer in elderly patients? A meta-analysis. CMAJ. 2007;176:649-54.

35. Murtola TJ, Tammela TL, Maattanen L, Huhtala H, Platz EA, Ala-Opas M, et al. Prostate cancer and PSA among statin users in the Finnish prostate cancer screening trial. Int J Cancer. 2010;127:1650-9.

36. Cuello FM, Kato CS, Diaz SD, Owen G. [Effects of statins in cancer]. Rev Med Chil. 2013;141:227-36.

37. Demierre MF, Higgins PD, Gruber SB, Hawk E, Lippman SM. Statins and cancer prevention. Nat Rev Cancer. 2005;5:930-42.

\section{Submit your next manuscript to BioMed Central and take full advantage of:}

- Convenient online submission

- Thorough peer review

- No space constraints or color figure charges

- Immediate publication on acceptance

- Inclusion in PubMed, CAS, Scopus and Google Scholar

- Research which is freely available for redistribution 